\title{
14
}

\section{DEVELOPING SOCIAL BENEFIT BONDS IN AUSTRALIA: THE NSW FAMILY AND COMMUNITY SERVICES EXPERIENGE}

\author{
Simone Walker \\ NSW Department of Family \\ and Community Services
}

In the Department of Families and Community Services (FACS), New South Wales, we have been working on a Social Benefit Bonds (SBB) pilot for two years, and it is now starting to come to fruition. ${ }^{1}$ The benefit that I am most proud of is that it really is about combining a new financial tool with - in our case- better outcomes for children and young people.

When this process first started, my role in FACS was Executive Director for the Service System Delivery area, which relates to funding and contracting. I was involved in the pilot because it was a very new and different way to contract. Subsequently, I have become the Executive Director for Out-of-Home Care; it has been a good marriage of roles and positions. This is a bold direction, and one which we are very proud of in NSW. It is groundbreaking because it centres

1 This paper is based on a talk delivered in 2013. The bonds and outcomes it discusses have been progressing since this time. 
on the ability to bring together new money (from investors), with outcomes for children and young people, in a better and safer way. That sort of alignment is something we do not get to work with very often.

\section{Children in out-of-home care}

In 2002 there were over 9,000 children in out-of-home care (Figure 14.1). These were children the NSW Children's Court had decided were not safe if they remained with their families. In June 2013, that number had more than doubled, rising to 18,400 . This is a significant population increase, requiring urgent action to find better and safer alternatives for this population. We have a strong reformist government at the moment (2015), and we have a number of reforms currently sitting in this space. Simultaneously, FACS is moving out of the business of direct service provision; we are transitioning all of our statutory out-of-home care to the non-government organisation (NGO) sector. This is the context in which we began to explore the introduction of SBBs.

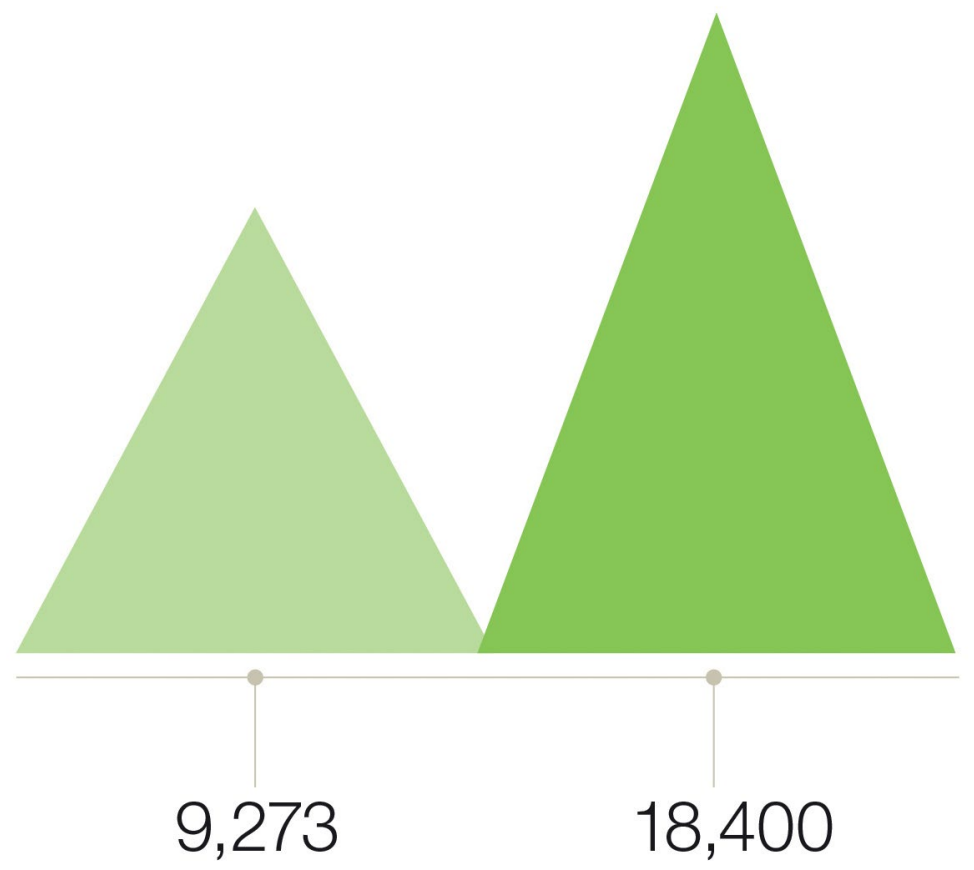

Figure 14.1. Number of children in out-of-home care in NSW, 2002 and 2013 Source: Family and Community Services, 2013, Transition Dashboard. 
This transition to the NGO sector probably will not have a dramatic effect on the population, but we anticipate that it will produce much better outcomes for children, partly because caseloads in NGOs are currently around 1:13, compared to $1: 28$ in Community Services. In order to reduce the population, we turned to SBBs, and especially a pilot investment scheme known as the Newpin bond on which we have worked closely with UnitingCare Burnside - a leading child and family support organisation in NSW. This bond is strongly focused on the restoration of children to their families. Because this is all about restoration and aligning the outcomes with the financial tool, an upfront assumption that we needed to make with this bond is that children are better off with their birth families when it is safe. We know that most children in out-of-home care have poor outcomes, especially when compared to children in similar circumstances who stay at home with their families of origin. When that is your underlying assumption, you are extremely motivated to make this work, and I think that has been a driving force in the partnership between UnitingCare Burnside and Community Services. Where it is suitable to return these children to their birth families, with the right support, the right energy and the right service provider, that is what we will try to do.

\section{How the bond works}

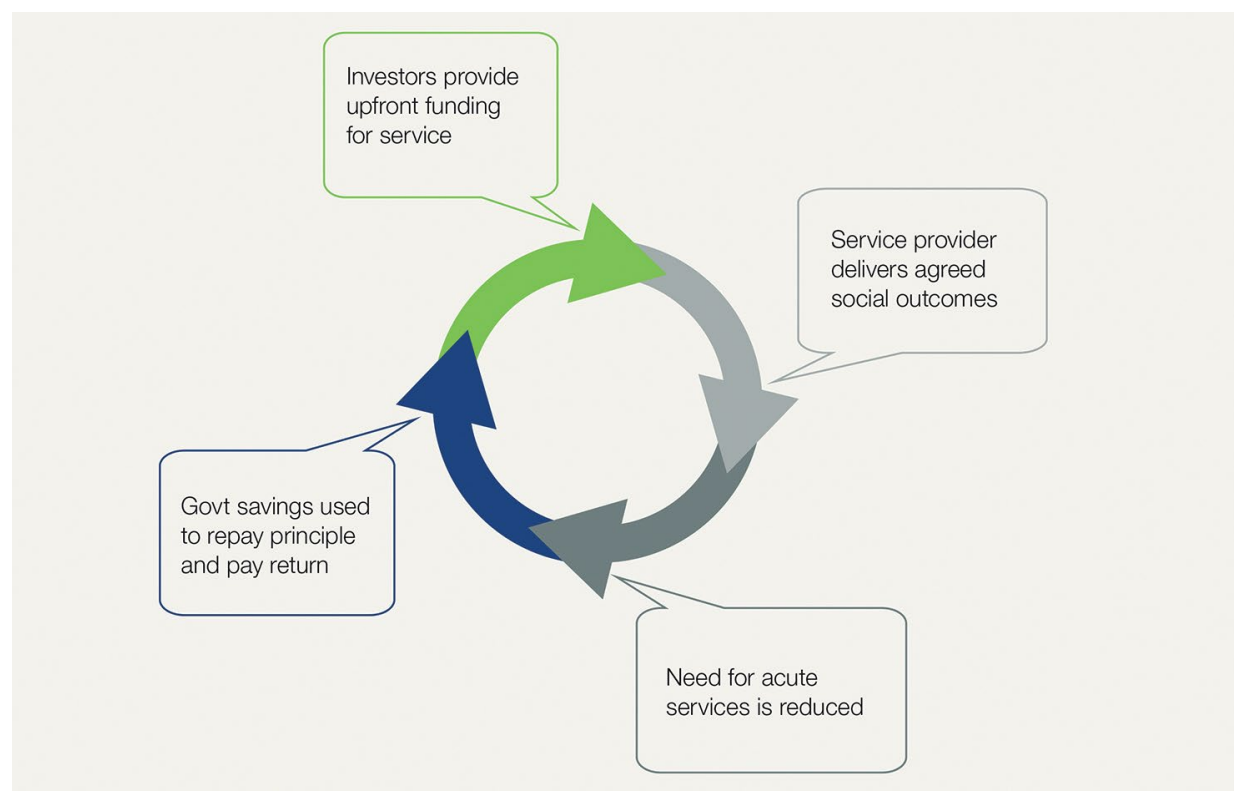

Figure 14.2. What is a social benefit bond?

Source: Cowling and Walker 2013. 
Figure 14.2 is a very simple diagram, and it might oversimplify the concepts and processes underlying SBBs, but it is a good basic starting point. First, beginning with the green arrow, investors interested in social outcomes provide the upfront funding for a given service or outcome. The Newpin bond through UnitingCare Burnside is a $\$ 7$ million bond; and we have an additional $\$ 10$ million bond with the Benevolent Society, which was extremely successful in the subscriptions (see below). The government's aim here was to tap into the development of the social finance sector to support additional or better out-of-home programs.

Second, the NGO service provider delivers an agreed social outcome. For this initial pilot, what we were looking for was a known provider, an organisation that had a proven track record - and that was UnitingCare Burnside. We needed to be able to say to them, 'We want to put the responsibility and a substantial part of the risk with you as the provider for doing this work'. The desired outcome we agreed is about returning children to their birth families. The principal benefit in this outcome, from a measurement point of view, is that it is binary: children are either in out-of-home care, or they are not. This is very important for the measurement of performance in relation to the bond, especially when taking into account a return to investors. Ultimately, returning children to their birth families in a safe and considered way will result in an improvement in clients' lives, reducing the need for acute services. Consider that for each child in outof-home care, even those with the simplest needs, an NGO receives $\$ 37,000$ a year. If a child comes into out-of-home care aged two and stays until they are 18 (as many do), the figures mount up exceeding half a million dollars per childand become especially high when you consider how many children NSW has in statutory care. Despite the additional support required by some birth families to keep the children at home with them safely, this is still a much better option for the NSW government (from both a financial and an outcomes perspective).

Third, it is the savings to government associated with these outcomes that are what really make the social bond work; some of the savings are returned to investors (as illustrated by the blue arrow in Figure 14.2). It is important to note that the returns are capped, because the idea of this bond is not for people to make extraordinary returns. This gives assurance to government, as well as to other people scrutinising the purpose of the bond, that this is not just a money creation scheme.

The key difference operating with the UnitingCare Burnside Newpin SBB is the availability of funding levels to which we had previously not had access. We are starting to see the untold potential of being able to tap into private funding sources as a way to get better social outcomes. We are very focused on performance outcomes and performance accountability, which goes to some of the comments made in John Wanna's introduction to this book. However, 
given the incredible energy it has taken to get the social bonds up, we are not able to consider any new bonds in the immediate future, but there is enormous potential here for other government agencies.

\section{The Newpin process - three different bonds, three different models}

The Newpin SBB was a twinkle in the eye of the previous government, but the O'Farrell-Baird governments in NSW have really taken it on; they are 100 per cent committed to this social bond innovation. A request for proposals was approved by Treasury in September 2011; after an evaluation process, proponents were selected in March 2012.

We currently have two bonds. The first is the UnitingCare Burnside SBB, called the Newpin bond, which has raised a $\$ 7$ million bond over seven years. The main focus is restoration, but it also includes family preservation services. The response from the market was an unknown in early days, although there was a considerable amount of market testing. We originally thought that philanthropists would be very interested in the bond process, but what we have discovered over time is that it has actually been more popular with 'real' investors who are looking for a return on their dollars, and for a whole range of reasons has been less attractive to philanthropic investors.

A second social bond is with the Benevolent Society, which is focused mainly on family preservation (i.e. preventing children from going into out-of-home care). Because there was an overwhelmingly positive response to the Newpin SBB, that has given us great confidence that the Benevolent Society SBB will also be wellreceived. It is a $\$ 10$ million bond over five years, and the Benevolent Society have partnered with Westpac and the Commonwealth Bank. It is a completely different financial model from Newpin, and there is a clear message here for us: there is massive opportunity in this space, but it needs to be something where people are passionate about the outcomes, because of the sheer amount of work that goes into making it happen.

It took two years to work out the financial models and other details. These were fit-for-purpose models, so it was very difficult to make the transition from one model to the other. In the Newpin bond, there will be annual payments for successful restorations. In contrast, the Benevolent Society will receive a large upfront payment, and then no further payment until five years later; at that point, we will measure how many of the children they worked with have ended 
up in out-of-home care. So there is a significant degree of risk to the agency at the five-year mark, but on the other hand there is a very large upfront payment, which represents a substantial risk to government.

As a result, we consider it crucial that we work with known substantial providers who are prepared to fully commit their staff, resources and reputation, but who are also big enough to sustain themselves throughout the process. This is not something that we could do with a small provider, or a niche innovative organisation.

A third bond related to recidivism, with Mission Australia, is still in the early stages of development. It is still on track, but there are some definite differences in relation to quantifying the savings for government. This is because of the nature of jail infrastructure - in out-of-home care we do not have to factor solid buildings infrastructure into the program, but jail infrastructure is an extra element that they are grappling with in the development of the recidivism bond.

\section{The negotiation phase}

Besides a lot of time and energy, a diverse set of skills was required to get this off the ground. We needed skilled project managers. We had significant input from people with expertise in specialist financial modelling, just to help us model what the potential savings to government were. Our economists and statisticians had to pull a vast amount of data to formulate a projection for children and young people. This was made more difficult by the questionable veracity of some of our data in FACS - it is not consistent, and timeliness and accuracy are not always high. This has certainly given us reasons to do a lot more work on our data systems.

We also worked closely with Crown solicitors. This is a commercial contract, something very different for us. Elements like the guarantee of referrals put a degree of requirement on FACS that we do not experience in our normal service agreements. In addition, we worked closely with representatives from Treasury. This process has been fantastic for the relationship between Community Services and Treasury, and there are clear benefits to knowing each other's business, understanding it and working so closely together on the financial modelling. Out-of-home care is the third biggest risk to the NSW government; our budget for 2013-14 is \$799 million-not an insignificant sum. We should engage Treasury more about why we are the biggest risk, but also why we are thinking of different ways to tackle the issues, and why we want their support and backing to find innovation. 
The other important thing was to have negotiators and executives meet frequently face-to-face. We met weekly for the last six to nine months, and we had to be able to make decisions in real time as the communication went forward - this feature of the process makes it very different from the way we work in most other circumstances. I needed to be able to say, 'I have the imprimatur in the room to make the decisions so that we can move these negotiations forward'. My role was to ensure that the Steering Committee and the Executive were aware of the direction, and their role back to me was to give me the imprimatur to push this forward. Knowing that our minister is 100 per cent committed was also important. Her message to us was: 'Find a way to make this happen', and our role in the room was to do just that.

\section{Counterfactuals and controls}

A significant part of the work has been building the outcomes and measurement framework, so this is where much of the resources were required. As I mentioned previously, a referral guarantee is something very new and different for FACS. We had to commit to delivering a certain number of families to the program, and the risk then transferred over to UnitingCare Burnside in their work with the families. FACS has had a chequered history with referral for some of our family programs, but it is something that we are working on consistently. This highlighted a need for quality data collection systems, and we have found that the Executive now wants to commit to more of that.

We also had to develop a counterfactual rolling control group, which became the basis of the measurement. We needed to work out how many children return home from out-of-home care, regardless of intervention. This process took many months, and ultimately, the figure we settled on was carefully negotiated. We as a government needed to be sure that we were not paying for outcomes that were going to occur even with no intervention, and UnitingCare Burnside needed to know that there was veracity in our figure so that they were achieving at a level where they would get a return for the investors. The weaknesses in our data systems were crucial here, because every time we felt our data let us down, it put us from a negotiated position to a worse place. What we determined, to the best of our ability, is that 25 per cent of children going into care will go home, regardless of the intervention that they receive. They are what we call our 'business as usual' group. Thus for any payment to be made, UnitingCare Burnside needs to achieve a restoration rate higher than that 25 per cent - that is a big ask for an agency, but one that they have absolutely committed to.

Another positive outcome of this program is the rolling control group. We will have a control group of 300 children at any point in time through the eight years, and we will move children through that group depending on their experience 
in out-of-home care. This will give us not only a sense of how many children go home with or without an intervention, it will also give us a great amount of data and detail. The nature of our systems at the moment means that this is essentially a manually driven control group. With 300 children in the group, we are working hard to build the supporting systems to make sure that we have accurate data. All of the data will be independently verified, because it is crucial in calculating the payment to Burnside, and then the return to the investors.

\section{Criticisms of the social bonds initiative: 'Cash for kids'?}

One criticism that has been presented to us internally from our case workers, and also from places like the Council of Social Service of New South Wales, is the risk of this program being perceived as 'cash for kids' - the idea that payment is made for each successful restoration. This is something that we did have to wrestle with during the planning and negotiation phases. We needed to ensure that there was no opportunity for gaming on either side of the negotiation. With this being a commercial contract, we needed to ensure that Community Services did not cherry pick the most difficult cases to refer to UnitingCare Burnside. We also needed to make sure that restorations were safe, that they were real, and that they were successful.

We have used the contract to make these specifications, so there are very solid criteria about the children that are referred. Firstly, there has to be agreement about each child transferred between FACS and Burnside. Secondly, successful restoration may be paid upon year two: we test the restoration in the following year, and if a child has gone back into out-of-home care during that year, the payment is reversed. That indicates how much pressure is upon Burnside, but also how much pressure is on the data - we need to be sure that we are tracking these children accurately. However, these arrangements have also served as an avowal that this program is absolutely about good outcomes and not, as some people have described, about cash for kids.

Implementing SBBs has been a very exciting opportunity, and so many times I have said to people, 'This is like being part of history'. Looking back, I simply underestimated how hard history can be to make. And yet, it has been exciting; it is something to get passionate about, because there is so much opportunity to make an impact. The chance to mix the part of the work that I love (good outcomes for children) with something new and different in contracting has been brilliant. I would encourage people to think about the opportunities that sit in their spaces, as well as the challenges that may come with them. 


\section{Reference}

Cowling, Sally and Simone Walker. 2013. 'NSW social benefit and bonds pilot.' NSW Government: Family and Community Services. Slide presentation at the ANZSOG conference 'Delivering under Pressure'. Brisbane, 6-8 August. 
This text is taken from Managing Under Austerity, Delivering Under Pressure, edited by John Wanna, Hsu-Ann Lee and Sophie Yates, published 2015 by ANU Press, The Australian National University, Canberra, Australia. 